\title{
ANNOUNCEMENT \\ Twenty-Third Annual Meeting of the Psychonomic Society
}

The Twenty-Third Annual Meeting of the Psychonomic Society will be held at the Hyatt Regency Hotel in Minneapolis, November 11-13, 1982. The call for papers was mailed to Society members during May 1982. The deadline for the receipt of abstracts is July 1, 1982. Papers dealing with the application of psychological science to realworld problems are encouraged. The program and hotel reservation forms will be mailed to members in the early fall. Also, the program will be printed in the September issue of the Bulletin of the Psychonomic Society. The Secretary-Treasurer, J. Bruce Overmier, may be contacted for further information at the Department of Psychology, University of Minnesota, Minneapolis, Minnesota 55455 [(612) 373-3430]. 